(2) Open Access Full Text Article

\title{
Improved cognitive functions after treatment with an oral appliance in obstructive sleep apnea
}

This article was published in the following Dove Press journal:

Nature and Science of Sleep

2I August 2012

Number of times this article has been viewed

\author{
Åke Tegelberg ${ }^{1,4,5}$ \\ Bo Wilhelmsson ${ }^{2}$ \\ Nina Erixon-Lindroth ${ }^{6}$ \\ Leif $\mathrm{H}$ Lindström ${ }^{3,4}$ \\ 'Department of Stomatognathic \\ Physiology, ${ }^{2}$ Department of \\ Otorhinolaryngology, ${ }^{3}$ Department \\ of Psychiatry, Central Hospital, \\ Västerås, Sweden; ${ }^{4}$ Centre for Clinical \\ Research, Uppsala University, Central \\ Hospital, Västerås, Sweden; ${ }^{5}$ Faculty \\ of Odontology, Malmö University, \\ Malmö, Sweden; ${ }^{6}$ Department of \\ Clinical Neuroscience, Karolinska \\ Institutet, Stockholm, Sweden
}

Objective: The objective of this study was to evaluate the effect of oral appliance (OA) treatment on cognitive functions in patients with obstructive sleep apnea (OSA).

Materials and methods: In a prospective study, 50 male patients with verified moderate-tosevere OSA received an OA with mandibular advancement. The cognitive functions assessed included working memory, vigilance, executive functioning, and mental pace, measured before as well as after 6 months of treatment. Somnography was used to measure physiological treatment effects. Forty-three patients completed the 6-month follow-up study.

Results: All domains of cognitive functioning measured improved after 6 months of treatment with an OA $(P<0.001)$. The apnea/hypopnea- and oxygen desaturation-indices decreased significantly after treatment $(P<0.01)$. An obvious treatment response was reached in $60 \%$ of the patients, and $54 \%$ of the patients had recovered ie, had normalized breathing during sleep.

Conclusion: OA with mandibular advancement is a treatment modality for the physiological symptoms of OSA, and may have a positive impact on cognitive functions, after only 6 months of treatment.

Keywords: clinical trial, cognition, oral appliance, sleep apnea, treatment

\section{Introduction}

Obstructive sleep apnea (OSA) is a chronic condition characterized by repeated collapse of the upper airway during sleep, and resulting recurrent episodes of apnea. ${ }^{1}$ One of the potential consequences of sleep fragmentation arising from the nocturnal hypoxia in OSA, is excessive daytime sleepiness, which influences functional performance during daytime..$^{1,2}$ OSA has been shown to be implicated in reduced daytime alertness, cognitive performance and quality of life. ${ }^{3-5}$ Sleepiness and cognitive impairment may be an important risk factor related to OSA (eg, in relation to traffic accidents) ${ }^{6,7}$

It has been found that during sleep, muscular tonic activity decreases and an increased collapsibility of the pharyngeal tissues occurs, narrowing the oro- and hypopharyngeal airways. ${ }^{8}$ Use of an oral appliance (OA) with a mandibular advancement causes stretch-induced activation in the pharynx, reducing soft tissue laxity and airway collapse. ${ }^{9} \mathrm{OA}$ is one of the current successful treatment modalities used to improve this sleep-related breathing impairment. ${ }^{10,11}$

Cognitive functioning in OSA has previously been evaluated with neurophysiological and neuropsychological measurements, and impairment has been confirmed. ${ }^{12,13}$ Studies have shown some improvement of cognitive functions after treatment of moderate-to-severe OSA with continuous positive airway pressure (CPAP), ${ }^{14,15}$ and after surgical procedure such as uvulopalatopharyngoplasty. ${ }^{16}$ However, there
Correspondence: Åke Tegelberg Faculty of Odontology, Malmö University, SE-205 06 Malmö, Sweden Tel +46 705 I75470 Email ake.tegelberg@mah.se 
is limited knowledge about changes in cognitive function following OA-treated OSA. The one previous randomized controlled trial study ${ }^{17}$ we are aware of showed improvement in vigilance and psychomotor speed.

We hypothesized that the cognitive impairment caused by OSA would be specifically sensitive to tests of frontal lobe dysfunction such as vigilance, executive functions and/or mental pace. We further postulated that if $\mathrm{OA}$ treatment were to be correlated with improved cognitive functioning in OSA, as has been shown with CPAP treatment, ${ }^{14}$ these results would strengthen the evidence for the recognition of OA as a valuable treatment modality, capable of reversing the negative consequences of OSA on cognitive functioning.

The aim of the study was to assess the effect of OA treatment on cognitive functions in patients with moderate and severe OSA.

\section{Patients and methods}

\section{Patients}

The study was approved by the ethics committee at the Faculty of Medicine at Uppsala University and was undertaken in agreement with the principles of the Declaration of Helsinki. All participants gave their written and verbal informed consent.

Patients between 20-65 years of age who had confirmed sleep apnea (OSA) ie, an apnea-hypopnea index (AHI) $\geq 10$, were eligible for inclusion in the study if they had sufficient dental support to anchor an OA (at least one premolar or molar tooth in both upper and lower jaws, and on both right and left sides), and no severely cariogenic, and/or a severely periodontal compromised dentition. The exclusion criteria were: severe cardiovascular, neurological, or respiratory disease; significant nasal obstruction; overbite of anterior teeth $>6 \mathrm{~mm}$; previous treatment for OSA by CPAP, or by uvulopalatopharyngoplasty surgical intervention, and; the presence of temporomandibular joint pain, or obvious myalgia in jaw function. Patients who fulfilled the inclusion criteria were treated with an $\mathrm{OA}$ with a mandibular advancement.

The study population included 50 male patients referred from the Ear, Nose and Throat department to the department of Stomatognathic Physiology, Central Hospital, Västerås, Sweden, for treatment of their somnographicallyverified OSA.

\section{Definitions}

Apnea was defined as the cessation of respiratory airflow for 10 seconds or longer. A hypopnea was said to have occurred when there was a $50 \%$ reduction of the airflow signal, combined with a decrease in hemoglobin oxygen saturation of at least $4 \%$. The apnea-hypopnea index (AHI) was defined as the average number of episodes of apnea and hypopnea per hour of sleep, and the oxygen desaturation index (ODI) was defined as the average number of episodes of oxygen desaturation of at least $4 \%$ per hour of sleep. OSA was defined as AHI $\geq 10$, and diagnosed in accordance with the guidelines established by the American Academy of Sleep Medicine Task Force. ${ }^{18}$ Treatment response was defined as the percentage of patients with a decrease in AHI of at least $50 \%$. Normalized breathing was defined as AHI $<10$.

\section{Somnography and sleepiness}

Somnographic measurements (sleep studies) were performed in the patients' home and while the patient slept - at baseline without OA and after 6 months of treatment with the OA inserted in the mouth. The following five variables were recorded simultaneously using a portable unit: ${ }^{19}$ hemoglobin oxygen saturation was measured using pulse oximetry via a finger probe; air flow were measured through the nose and also, through the mouth using a thermistor; respiratory movements were determined by bioimpedance measurements registered by electrodes placed on each side of the chest, and; body position was established with a sensor on the chest. Sleep studies lasting less than 4 hours were not accepted; in such cases, a second measurement was undertaken.

The self-administrated questionnaire, the Epworth Sleepiness Scale (ESS) was used to measure the subject's general level of daytime sleepiness. The questionnaire consisted of eight questions about daily situations. Each question was rated on a scale of $0-3$, where $3=$ high chance of dozing. ${ }^{20,21}$ At follow-up, patients were additionally asked to report subjective evaluation of change in daytime sleepiness on 7-point scale ranging from very much improved to very much worsened. The frequency of use (nights/week) of the OA was also reported.

\section{Tests of cognitive functions}

The cognitive functions were assessed as described below in detail. The two test sessions, at baseline and after 6 months of treatment were carried out between 1 and 4 pm for consistency, and to control for variations in daytime sleepiness. The tests were performed under the supervision of an experienced research nurse who was blind to the patient's somnographic result. The first two tests $(\mathrm{A}, \mathrm{B})$ were computerized and the third (C) was a paper-and-pen version. 


\section{Working memory test (WM)}

This is a test of executive functioning, measuring visual discrimination, spatial orientation, vigilance and working memory. The test was modeled after the delayed-response task devised by Park and Holzman ${ }^{22}$ and Erixon-Lindroth..$^{23}$ The test consisted of 32 trials in which patients were asked to remember the position of a target while performing a distraction task. At the start of the test, a black circle, the target, was displayed on a computer screen for $200 \mathrm{~ms}$ (the location of the target varied randomly from trial to trial). While the patient kept the target position in mind for 30 seconds, a distraction task was performed. In this task, a three-digit number (eg, 352) appeared in the center of the screen and counted down in steps of two, displaying a new number every second (ie, 352, 350, 348); however, at random times ( $30 \%$ of cases), the number appearing on the screen did not differ from the preceding number by two units (ie, 352, 350, 349). The task was to detect such deviations from the typical sequence. The distraction task lasted for 30 seconds and was terminated by the appearance of eight empty circles. One of which was placed in the position where the target had appeared. The patient was asked to drag the marker to the correct position and click to confirm the answer, to complete the trial. The test session involved 32 such trials, and the patient was allowed to rest after 16 trials.

The distraction task presented 30 new numbers per trial for a total of 960 instances. A correct response was registered for trials where the patient did not click the mouse when the computer counted down in steps of two, and for trials where patients clicked the mouse in case of a deviation from the typical counting-down sequence. The outcome measure was expressed as the percentage of correct responses.

\section{Continuous Performance Test, Identical Pairs Version (CPT-IP)}

The CPT-IP measures sustained attention..$^{24}$ Computergenerated visual stimuli consisting of four-digit numbers (eg, 2463) were flashed on the screen for $50 \mathrm{~ms}$ at a constant rate of 1 per second, and were presented in sequences of 150 trials. Computer-generated visual stimuli consisting of four-digit numbers (eg, 2463) were flashed on the screen for $50 \mathrm{~ms}$ at a constant rate of 1 per second, and were presented in sequences of 150 trials. In 30 "target" trials (20\%), the fourdigit number was identical (same digits, and same sequence) to the four-digit number preceding it. In 28 "catch" trials, the four-digit number presented was very similar, but was not identical to it to the four-digit number of the preceding trial (eg, 2463 and 2643). The task was to respond as fast as possible whenever two identical four-digit numbers were presented in a row by a finger-lift from the response key held in the dominant hand.

Three blocks of 150-trial series were undertaken during the test session. Responses to target trials were scored as correct detection (hits). Responses to catch trials were considered a specific type of commission error, referred to as false alarms. The number of correct detections (hits), false alarms, the d-prime (the quotient of hits/false alarms that indicated the response sensitivity for discrimination of target from nontarget stimuli) and reaction time were recorded.

\section{Trail-Making Test (TMT), part A and part B}

The TMT is a paper-and-pencil test to assess fine motor speed, visual search, mental pace and frontal executive function. ${ }^{25} \mathrm{In}$ part A, the patient was asked to connect as quickly as possible, 20 numbered circles randomly plotted on a sheet, by drawing a pencil line starting at number 1 and ending on number 20 . In part $\mathrm{B}$, the patient was again asked to draw a line connecting a series of circles, but was required to alternate between numbers and letters (ie, starting on a circle numbered 1 , and then circle labeled $\mathrm{A}$, then to circle numbered 2 , thereafter to circle $\mathrm{B}$, etc).

For both Parts (A) and (B), the time to complete this task was recorded in seconds, from the start to the completion of the trial.

\section{Retest evaluation of cognitive function}

To test the reliability of the cognitive tests, we re-tested a randomized sample of the patients $(n=19)$ before treatment. The retest was performed after 2 weeks, under the same conditions and at the same time of the day as the first test.

\section{Treatment with mandibular advancement OA}

The clinical management and the treatment with OA are described in detail in an earlier paper. ${ }^{26}$ In the present study, all patients were treated by two dentists with long experience of working with appliance treatment. One dental technician was responsible for manufacturing all the appliances used. The appliances were manufactured in one-piece heat-cured acrylic polymer (Figure 1). The appliances advanced the mandible from a position of intercuspidation to $50 \%$ of the patients' individual protrusive capacity. 


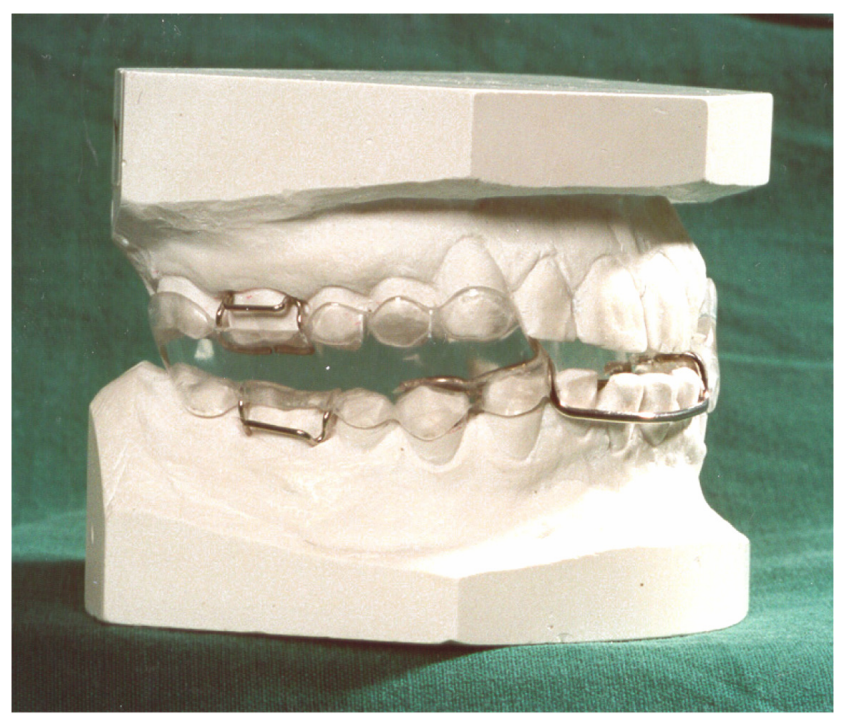

Figure I The oral appliances used in this study were manufactured in one-piece heat-cured acrylic polymer.

\section{Statistics}

Numerical results are expressed as means with $95 \%$ confidence intervals $(95 \% \mathrm{CI})$. Differences in somnographic variables between the two groups, at baseline and after 6 months of treatment for moderate and severe OSA were tested using The Wilcoxon signed-rank test. The chi-square test was used to compare differences in response and recovery between the two groups. Wilcoxon signed-rank test was used to test differences of cognitive functions between groups, and between results obtained before and after 6 months of treatment. Cronbach's alpha test was used as intraclass correlation coefficient (ICC) for test of relationship between the two pretreatments of the cognitive functions. $P<0.05$ was considered statistically significant.

\section{Results}

The mean age (range) was 52 years ( $20-65$ years) and the mean value for body mass index was $29.9(28.5-31.3)$ before the intervention. Obesity, that is, a body mass index $\geq 30$ was observed in $50 \%$ of the patients. Severe OSA, AHI $>30$, was diagnosed in $70 \%$ of the patients, and the remaining $30 \%$ were diagnosed as moderate OSA (AHI $>20$ but $<30$ ).

Out of the 50 participating patients, 43 (86\%) completed all the follow-up evaluations. Seven patients withdrew before the follow-up session for the following reasons: three received CPAP-treatment as an alternative; two could not tolerate the $\mathrm{OA}$; one received other dental treatments during the treatment period, and one did not use the appliance. Two patients with severe OSA did not perform the cognitive tests after treatment.

All patients had a mandibular advancement capability of at least $6 \mathrm{~mm}$ and mean value was $10.3 \mathrm{~mm}$ (standard deviation $[\mathrm{SD}] \pm 2.5)$. The patients used their $\mathrm{OA}$ on average 6.6 nights/week (median 7.0) and all except one used the OA regularly, ie, $\geq 5$ nights/week.

At baseline the mean ESS rating was $11.2(\mathrm{SD}=4.1)$ and after treatment this was reduced to $6.8(\mathrm{SD}=4.5)$, and this difference reached statistical significance in patients whose breathing had normalized $(P<0.001)$ as well as in patients whose breathing had not reached the normalization level $(P<0.02)$.

\section{Subjective evaluation of treatment effect}

A substantial decrease in daytime sleepiness was reported in $44 \%$ of the patients. The decrease was more frequently reported (53\%) among those patients who had normalized breathing. None of the patients reported increases in either: daytime sleepiness, frequency of apneas, or snoring, at the time of follow-up.

\section{Treatment effect on somnographic variables}

After 6 months of treatment, the mean AHI and ODI values decreased significantly compared with the pretreatment values in both the moderate and severe OSA group (Table 1).

A treatment response was reached in $67 \%$ of the moderate OSA group and in 57\% of the severe OSA group.

Table I Somnographic values at baseline and after 6 months of treatment in patients with obstructive sleep apnea (OSA) who completed the follow-up

\begin{tabular}{|c|c|c|c|c|c|c|}
\hline & \multicolumn{3}{|l|}{ Baseline } & \multicolumn{3}{|c|}{ After 6 months } \\
\hline & $\begin{array}{l}\text { Total } \\
\mathrm{n}=45\end{array}$ & $\begin{array}{l}\text { Moderate OSA } \\
n=15\end{array}$ & $\begin{array}{l}\text { Severe OSA } \\
n=30\end{array}$ & $\begin{array}{l}\text { Total } \\
\mathrm{n}=45\end{array}$ & $\begin{array}{l}\text { Moderate OSA } \\
n=15\end{array}$ & $\begin{array}{l}\text { Severe OSA } \\
n=30\end{array}$ \\
\hline $\mathrm{AHI}$ & $40.9(16.0)$ & $23.0(2.7)$ & $48.6(12.7)$ & $18.0(17.3)^{\mathrm{a}}$ & $11.2(7.8)^{b}$ & $21.5(19.6)^{\mathrm{a}}$ \\
\hline ODI & $39.7(21.0)$ & $22.3(9.8)$ & $47.4(20.1)$ & I7.3 $(17.2)^{\mathrm{a}}$ & $10.5(7.7)^{\mathrm{b}}$ & $20.7(19.6)^{\mathrm{a}}$ \\
\hline
\end{tabular}

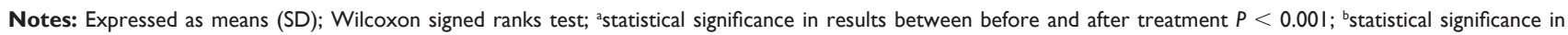
results between before and after treatment $P<0.01$.

Abbreviations: OSA, Obstructive sleep apnea; AHI, apnea/hypopnea index; ODI, oxygen saturation index. 
In the moderate OSA group, $60 \%$ of patients reached the normalization level, compared with $43 \%$ whose breathing reached the normalization level in the severe OSA group.

\section{Treatment effect on cognitive functions}

The results of cognitive functioning tests before and after 6 months of treatment with OA are presented in Table 2. The corresponding results for the subgroup of patients with severe OSA are shown in Table 3. Table 4 presents the effect of OA on the somnographic outcome in relation to the effect on cognitive functions.

After 6 months of treatment with OA, a significant improvement was found for the distraction task of the WM test, measuring sustained attention/vigilance $(P<0.001)$ (Table 2). No effect was found for the memory score. A significant improvement was also seen in the CPT, another test of sustained attention/vigilance, following 6 months of treatment $(P<0.001)$. In the TMT, Part A, a significant improvement was found in motor speed $(P<0.001)$, but not in the TMT, Part B. Notably, the results of the subgroup of patients with severe OSA were generally similar to the total group of patients, and showed an improvement in sustained attention/vigilance and motor speed after treatment with OA (Table 3); however, patients with severe OSA also demonstrated an improvement in the TMT, Part B, that was not seen in the total group. We found no relationship between the effect of OA on somnographic changes and cognitive improvement (Table 4). Patients whose breathing was normalized in AHI did not significantly differ from those whose breathing did not normalize, with regard to cognitive functioning.

Table 2 Cognitive function tests before and after treatment of obstructive sleep apnea with an oral appliance

\begin{tabular}{|c|c|c|c|}
\hline & $\begin{array}{l}\text { Before } \\
n=43\end{array}$ & $\begin{array}{l}\text { After } \\
n=43\end{array}$ & $\begin{array}{l}\text { Difference } \\
\text { before and after } \\
6 \text { months, } P \text {-value }\end{array}$ \\
\hline \multicolumn{4}{|l|}{ WM } \\
\hline Memory score & $88.2(10.8)$ & $81.8(11.5)$ & NS \\
\hline Distraction task ${ }^{\mathrm{a}}$ & $85.4(8.1)$ & $87.7(8.2)$ & $P<0.001$ \\
\hline \multicolumn{4}{|l|}{ CPT-IP } \\
\hline Correct counting & 53.1 (22.9) & $62.7(19.6)$ & $P<0.001$ \\
\hline False alarm ${ }^{\mathrm{a}}$ & $17.8(12.8)$ & $18.3(13.6)$ & NS \\
\hline D'prime $^{\mathrm{b}}$ & I.20I (0.669) & $1.419(0.766)$ & $P=0.015$ \\
\hline \multicolumn{4}{|l|}{ TMT } \\
\hline Part $A^{c}$ & $34.6(11.3)$ & $29.0(11.0)$ & $P<0.001$ \\
\hline Part $B^{c}$ & $84.9(32.8)$ & $75.2(27.3)$ & NS \\
\hline
\end{tabular}

Notes: Expressed as means (SD); Wilcoxon signed ranks test; ${ }^{\text {aexpressed as a }}$ percentage; 'quotient hits/false alarms; ' $e x p r e s s e d$ as seconds.

Abbreviations: WM, Working Memory test; CPT-IP, Continuous Performance Test, Identical Pairs Version; TMT, Trail-Making Test.
Table 3 Cognitive function tests before and after treatment with an oral appliance in patients with severe obstructive sleep apnea

\begin{tabular}{|c|c|c|c|}
\hline & $\begin{array}{l}\text { Before } \\
n=28\end{array}$ & $\begin{array}{l}\text { After } \\
n=28\end{array}$ & $\begin{array}{l}\text { Difference } \\
\text { before and after } \\
6 \text { months, } P \text {-value }\end{array}$ \\
\hline \multicolumn{4}{|l|}{ WM } \\
\hline Memory score & $81.3(14.4)$ & $82.4(10.7)$ & NS \\
\hline Distraction task ${ }^{\mathrm{a}}$ & $83.8(8.7)$ & $87.6(8.5)$ & $P<0.001$ \\
\hline \multicolumn{4}{|l|}{ CPT-IP } \\
\hline Correct counting ${ }^{a}$ & $57.1(21.2)$ & $66.8(19.2)$ & $P<0.001$ \\
\hline False alarma & $18.0(11.9)$ & $19.9(15.4)$ & NS \\
\hline$D^{\prime}$ prime $^{\mathrm{b}}$ & $1.267(0.780)$ & $1.510(0.869)$ & $P=0.031$ \\
\hline \multicolumn{4}{|l|}{ TMT } \\
\hline Part $A^{c}$ & $33.1(10.1)$ & $27.6(8.9)$ & $P<0.001$ \\
\hline Part $B^{c}$ & $84.1(35.9)$ & $70.9(25.9)$ & $P<0.006$ \\
\hline
\end{tabular}

Notes: Expressed as means (SD); Wilcoxon signed ranks test; ${ }^{a}$ expressed as a

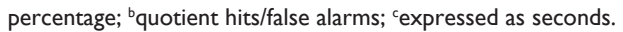

Abbreviations: WM, Working Memory test; CPT-IP, Continuous Performance Test; Identical Pairs Version; TMT, Trail-Making Test.

\section{Retest evaluation of cognitive function}

The reliability between the two pretreatment evaluations of the cognitive tests was considered good (ie, ICC > 0.7). In general there was high agreement in the test-retest scores, both in WM tests ( 0.71 and 0.93$)$ and continuous performance tests $(0.88,0.56$ and 0.79$)$, but not in either of the two parts of the TMT (0.5 and 0.55$)$.

\section{Discussion}

A number of previous studies have assessed the wide range of cognitive deficits associated with OSA. ${ }^{27}$ There are several interesting hypotheses suggesting the underlying mechanisms including, alterations in hippocampal metabolism, ${ }^{28}$ white matter lesions, ${ }^{28}$ and subcortical damage. ${ }^{29}$ Considerable discrepancies exist between different studies concerning the type and degree of dysfunctions that are associated with OSA. ${ }^{11}$ Some studies show decreased cognitive performance very similar to that which is observed after sleep deprivation. ${ }^{30,31}$

We accepted the plausibility of the hypothesis that this neuropsychological dysfunction in the brain may be due to ischemic damage in the frontal lobes, ${ }^{32,33}$ and therefore deliberately selected tests targeted to detect different prefrontal and frontal dysfunctions. Naegele et $\mathrm{al}^{5}$ showed that most cognitive deficits and learning disabilities found in OSA returned to normal following 4-6 months of treatment with CPAP, and other studies have confirmed at least partial reversibility of the cognitive dysfunction in OSA patients after CPAP treatment. ${ }^{32,34,35}$ However, short-term memory remained unchanged in the study by Naegele et al. ${ }^{5}$ This finding could indicate that the frontal lobe systems involved 
Table 4 Difference of somnographic treatment outcome and the influence on cognitive function tests

\begin{tabular}{|c|c|c|c|}
\hline & $\begin{array}{l}\text { Normalized }(\mathrm{AHI} \leq \mathrm{I0}) \\
\mathrm{n}=24\end{array}$ & $\begin{array}{l}\text { Not normalized }(\mathrm{AHI}>10) \\
n=19\end{array}$ & $\begin{array}{l}\text { Difference between responders vs } \\
\text { nonresponders, } P \text {-value }\end{array}$ \\
\hline \multicolumn{4}{|l|}{ WM } \\
\hline Memory score ${ }^{a}$ & I.I (I4.6) & $-1.5(12.4)$ & NS \\
\hline Distraction task ${ }^{a}$ & $2.6(3.6)$ & $0.4(6.8)$ & NS \\
\hline \multicolumn{4}{|l|}{ CPT-IP } \\
\hline Correct counting ${ }^{a}$ & $10.5(15.6)$ & $8.4(16.2)$ & NS \\
\hline False alarm ${ }^{a}$ & $1.8(14.2)$ & $-0.6(18.4)$ & NS \\
\hline D'prime ${ }^{\mathrm{b}}$ & $0.364(0.593)$ & $0.158(0.543)$ & NS \\
\hline \multicolumn{4}{|l|}{ TMT } \\
\hline Part $A^{c}$ & $-6.3(9.5)$ & $-3.3(7.8)$ & NS \\
\hline Part $B^{c}$ & $-11.0(26.9)$ & $-3.2(32.1)$ & NS \\
\hline
\end{tabular}

Notes: Expressed as means (SD); Chi-square test. Responders = normalized; a expressed as a percentage; bquotient hits/false alarms; 'expressed as seconds.

Abbreviations: AHI, Apnea/hypopnea index; WM, Working Memory test; CPT-IP, Continuous Performance Test, Identical Pairs Version; TMT, Trail-Making Test.

in short-term memory functions may be irreversibly damaged by OSA. Alternately, it is also possible that the brain needs a longer time for recovery. There are also studies showing positive results of uvulopalatopharyngoplasty surgery on cognitive functions, ${ }^{16,36}$ but little on the effects of OA on cognitive functions in OSA. ${ }^{17,37}$

Previous studies by our group found a normalizing effect on physiological values after treatment with OA in approximately $80 \%$ of patients with mild to moderate OSA and in $50 \%-60 \%$ of patients with severe OSA, ${ }^{38-40}$ consistent with other studies. ${ }^{11}$

Adherence to the treatment is a critical factor in treatment success. This was made obvious in a study of Tegelberg et $\mathrm{al}^{26}$, where pathological somnographic values recurred in $74 \%$ of the patients following cessation of use of the OA. In this earlier study, somnographic values were measured one night while the patient slept with an OA inserted, and the next night without (No washout period was used between the two measurements.), and explanation for discontinuation of treatment was not given. Compliance in use of the OA in the current study was comparable with that in other studies with similar follow-up time. ${ }^{38,40}$ The majority of patients in the study used the OA regularly, which demonstrates that the acceptance of the treatment modality was good. The fact that our study included 14\% dropouts strongly suggests that not everyone is comfortable with an intra-OA and that this treatment modality will not be successful for all patients with OSA.

ESS values less than 8 are classified as normal, values between 8 and 14 are considered clinically significant, and values between 15 and 24 indicate excessive daytime sleepiness and serious OSA. ${ }^{19,20}$ In this study the pathological baseline-ESS values had normalized at the time of follow-up, indicating that reductions in daytime sleepiness could be observed after 6 months of treatment. After 6 months of treatment with OA, improvements were also observed in results from several of the cognitive tests, in the areas of mental and motor speed, as well as vigilance. Vigilance was demonstrated by results of both the working memorydistraction task as well as the continuous performance test (CTP-IP). Both mental and motor speeds were demonstrated by results of TMT, Part A, which also showed improvement after 6 months of treatment. Since this test measures complex visual scanning, tracking and visuospatial ability, we conclude that OA improves psychomotor speed, agility, and selected and sustained attention, as well as coordination, qualities important for a normal daily life. An improvement was also seen in the more complex TMT, Part B, but only for patients with a severe OSA, and not when both moderate and severe OSA-patients were considered as a group. The data suggest that TMT, Part B (considered to be a test of frontal executive function), is only sensitive for the most severe cases of OSA. No improvement was seen for the memory score of the WM test. These findings suggest that these more complex executive dysfunctions may be reversible, since they can be changed following use of an OA.

In a recent study by Alchanatis et $a 1,{ }^{41}$ cognitive function focusing on attention/alertness tests, was assessed in patients with OSA and a control group. The investigators showed that participants over the cut-off age of 50 years showed a more severe cognitive reduction when compared with age-matched controls, whereas younger patients showed similar cognitive performance as their age-matched controls. It may be that the changes in cognition observed in the current study would have shown another pattern and been even greater, had younger patients been included. One limitation in our study is the lack of matched controls. Cognitive scores collected in community-based epidemiological studies ${ }^{42,43}$ 
suggest that cognition is minimally affected in mild sleep disordered breathing, but decrements become moderate to large in clinical samples of patients with OSA. In a sample of middle-aged men and women who had mild to moderate levels of sleep-disordered breathing but who were free of clinically diagnosed OSA, cognitive performance was unrelated to sleep-disordered breathing. Investigators concluded that it may be that older adults who experience a mild degree of sleep-disordered breathing, and perhaps minimal daytime sleepiness are able to function in daily life without measurable cognitive impairment. ${ }^{44}$

A problem in testing cognitive function several times is the learning effect of repeated testing. In the present study, we found a high ICC between the test-retest results for the WM and continuous performance-identical pair tests, indicating a minimal learning effect without any clinical significance. A learning effect was present for TMT-retest (which showed no significant correlations when tested 2 weeks apart) although it is less likely that this effect was still present after 6 months.

Limitations of the present case-control study are the lack of normative data for the cognitive tests. However, we found several interesting and significant differences in the measured variables, even in this limited number of patients with OSA. Cognitive impairment associated with OSA has previously been shown. This study extended these findings further, by comparing cognitive functions before and after treatment with OA, using the patients as their own controls. The standard deviations were relatively high in the current study indicating a large variation between subjects included in the study.

Recent functional imaging studies suggest that patients with OSA recruit different brain regions and activate these differently, compared with healthy controls. ${ }^{45,46}$ These studies also suggest neural compensatory mechanisms to be present among patients with OSA, and that the compensatory hyperactivity is reversible after effective treatment. ${ }^{47}$ Given that this field of study is new, we hope that our data will contribute to increased understanding of how the brain may compensate, and use different strategies to solve cognitive tasks. Further investigation in this field is warranted, to validate our findings.

In conclusion, we have found that treatment with OA had a positive impact on certain cognitive functions in patients with OSA, specifically, improved vigilance/sustained attention, motor and mental speed. We also found improved frontal executive functions in the patients with severe OSA. Thus, in parallel to ameliorating physiological variables
(AHI and ODI), OA ameliorates cognitive function as well. In the context of increasing use of this treatment modality worldwide, these findings suggest that OA can be important in the treatment for OSA and the diminished cognitive functions associated with OSA, that have impact on the performance of everyday and occupational tasks, and on the quality of life.

\section{Acknowledgments}

The project was financially supported by grants from the County of Västmanland, Sweden.

The authors wish to thank Dr Olle Vestling for performing a great part of the treatment with the oral appliances, research assistant Per Hagström for performing the executive functioning tests, and Petra Wahlén for assistance with the statistical analysis.

\section{Disclosure}

None of the authors have declared any conflict of interest.

\section{References}

1. Bassiri AG, Guilleminault C. Clinical features and evaluation of obstructive sleep apnoea-hypopnoea syndrome. In: Kryger MH, Roth T, Dement WC, editors. Principles and Practice of Sleep Medicine. 3rd ed. Philadelphia: WB Saunders Co; 2000:869-878.

2. Ulfberg J, Carter N, Talbäck M, Edling C. Excessive daytime sleepiness at work and subjective work performance in the general population and among heavy snorers and patients with obstructive sleep apnea. Chest. 1996;110(3):659-663.

3. Beebe DW, Gozal D. Obstructive sleep apnea and the prefrontal cortex: towards a comprehensive model linking nocturnal upper airway obstruction to daytime cognitive and behavioral deficits. J Sleep Res. 2002;11(1):1-16.

4. Engleman HM, Douglas NJ. Sleep. 4: Sleepiness, cognitive function, and quality of life in obstructive sleep apnoea/hypopnoea syndrome. Thorax. 2004;59(7):618-622.

5. Naëgelé B, Thouvard V, Pépin JL, et al. Deficits of cognitive executive functions in patients with sleep apnea syndrome. Sleep. 1995;18(1): $43-52$.

6. Findley L, Unverzagt M, Guchu R, Fabrizio M, Buckner J, Suratt P. Vigilance and automobile accidents in patients with sleep apnea or narcolepsy. Chest. 1995;108(3):619-624.

7. Young T, Blustein J, Finn L, Palta M. Sleep-disordered breathing and motor vehicle accidents in a population-based sample of employed adults. Sleep. 1997;20(8):608-613.

8. Hudgel DW. The role of upper airway anatomy and physiology in obstructive sleep apnea. Clin Chest Med. 1992;13(3):383-398.

9. Ono T, Lowe AA, Ferguson KA, Pae EK, Fleetham JA. The effect of the tongue retaining device on awake genioglossus muscle activity in patients with obstructive sleep apnea. Am J Orthod Dentofacial Orthop. 1996;110(1):28-35.

10. Ferguson KA, Cartwright R, Rogers R, Schmidt-Nowara W. Oral appliances for snoring and obstructive sleep apnea: a review. Sleep. 2006;29(2):244-262.

11. Lim J, Lasserson TJ, Fleetham J, Wright J. Oral appliances for obstructive sleep apnoea [review]. Cochrane Database Syst Rev. 2006; 1:CD004435.

12. Engleman H, Joffe D. Neuropsychological function in obstructive sleep apnoea. Sleep Med Rev. 1999;3(1):59-78. 
13. Saunamäki T, Jehkonen M. A review of executive functions in obstructive sleep apnea syndrome. Acta Neurol Scand. 2007;115(1):1-11.

14. Borak J, Cieślicki JK, Koziej M, Matuszewski A, Zieliński J. Effects of CPAP treatment on psychological status in patients with severe obstructive sleep apnoea. J Sleep Res. 1996;5(2):123-127.

15. Engleman HM, Kingshott RN, Wraith PK, Mackay TW, Deary IJ, Douglas NJ. Randomized placebo-controlled crossover trial of continuous positive airway pressure for mild sleep Apnea/Hypopnea syndrome. Am J Respir Crit Care Med. 1999;159(2):461-467.

16. Lojander J, Kajaste S, Maasilta P, Partinen M. Cognitive function and treatment of obstructive sleep apnea syndrome. J Sleep Res. 1999;8(1): 71-76.

17. Naismith SL, Winter VR, Hickie IB, Cistulli PA. Effect of oral appliance therapy on neurobehavioral functioning in obstructive sleep apnea: a randomized controlled trial. J Clin Sleep Med. 2005;1(4):374-380.

18. Redline S, Tosteson T, Boucher MA, Millman RP. Measurement of sleep-related breathing disturbances in epidemiologic studies. Assessment of the validity and reproducibility of a portable monitoring device. Chest. 1991;100(5):1281-1286.

19. Johns MW. A new method for measuring daytime sleepiness: the Epworth sleepiness scale. Sleep. 1991;14(6):540-545.

20. Johns MW. Reliability and factor analysis of the Epworth Sleepiness Scale. Sleep. 1992;15(4):376-381.

21. Sleep-related breathing disorders in adults: recommendations for syndrome definition and measurement techniques in clinical research. The Report of an American Academy of Sleep Medicine Task Force. Sleep. 1999;22(5):667-689.

22. Park S, Holzman PS. Schizophrenics show spatial working memory deficits. Arch Gen Psychiatry. 1992;49(12):975-982.

23. Erixon-Lindroth N. PET studies of the dopamine system in relation to cognitive functions. Stockholm, Sweden: Karolinska Institute; (doctoral thesis). 2007:21-22.

24. Cornblatt BA, Risch NJ, Faris G, Friedman D, Erlenmeyer-Kimling L. The Continuous Performance Test, identical pairs version (CPT-IP): I. New findings about sustained attention in normal families. Psychiatry Res. 1988;26(2):223-238.

25. Reitan RM, Wolfson D. The Halstead-Reitan Neuropsychological Test Battery: Theory and Clinical Interpretation. 2nd ed. Tucson: Neuropsychological Press; 1993.

26. Tegelberg A, Wilhelmsson B, Walker-Engström ML, et al. Effects and adverse events of a dental appliance for treatment of obstructive sleep apnoea. Swed Dent J. 1999;23(4):117-126.

27. Décary A, Rouleau I, Montplaisir J. Cognitive deficits associated with sleep apnea syndrome: a proposed neuropsychological test battery. Sleep. 2000;23(3):369-381.

28. Bartlett DJ, Rae C, Thompson CH, et al. Hippocampal area metabolites relate to severity and cognitive function in obstructive sleep apnea. Sleep Med. 2004;5(6):593-596.

29. Antonelli Incalzi R, Marra C, Salvigni BL, et al. Does cognitive dysfunction conform to a distinctive pattern in obstructive sleep apnea syndrome? J Sleep Res. 2004;13(1):79-86.

30. Nilsson JP, Söderström M, Karlsson AU, et al. Less effective executive functioning after one night's sleep deprivation. J Sleep Res. 2005; 14(1):1-6.

31. Verstraeten E, Cluydts R. Executive control of attention in sleep apnea patients: theoretical concepts and methodological considerations. Sleep Med Rev. 2004;8(4):257-267.

Nature and Science of Sleep

\section{Publish your work in this journal}

Nature and Science of Sleep is an international, peer-reviewed, open access journal covering all aspects of sleep science and sleep medicine, including the neurophysiology and functions of sleep, the genetics of sleep, sleep and society, biological rhythms, dreaming, sleep disorders and therapy, and strategies to optimize healthy sleep. The journal welcomes
32. Thomas RJ, Rosen BR, Stern CE, Weiss JW, Kwong KK. Functional imaging of working memory in obstructive sleep-disordered breathing. J Appl Physiol. 2005;98(6):2226-2234.

33. Aloia MS, Arnedt JT, Davies JD, Riggs RL, Byrd D. Neuropsychological sequelae of obstructive sleep apnea-hypopnea syndrome: a critical review. J Int Neuropsychol Soc. 2004;10(5):772-785.

34. Engleman HM, Kingshott RN, Martin SE, Douglas NJ. Cognitive function in the sleep apnea/hypopnea syndrome (SAHS). Sleep. 2000; 23 Suppl 4:S102-S108.

35. Ferini-Strambi L, Baietto C, Di Gioia MR, et al. Cognitive dysfunction in patients with obstructive sleep apnea (OSA): partial reversibility after continuous positive airway pressure (CPAP). Brain Res Bull. 2003;61(1):87-92.

36. Dahlöf P, Norlin-Bagge E, Hedner J, Ejnell H, Hetta J, Hällström T. Improvement in neuropsychological performance following surgical treatment for obstructive sleep apnea syndrome. Acta Otolaryngol. 2002;122(1):86-91.

37. Engleman HM, McDonald JP, Graham D, et al. Randomized crossover trial of two treatments for sleep apnea/hypopnea syndrome: continuous positive airway pressure and mandibular repositioning splint. Am J Respir Crit Care Med. 2002;166(6):855-859.

38. Wilhelmsson B, Tegelberg A, Walker-Engström ML, et al. A prospective randomized study of a dental appliance compared with uvulopalatopharyngoplasty in the treatment of obstructive sleep apnoea. Acta Otolaryngol. 1999;119(4):503-509.

39. Tegelberg Å, Walker-Engström ML, Vestling O, Wilhelmsson B. Two different degrees of mandibular advancement with a dental appliance in treatment of patients with mild to moderate obstructive sleep apnea. Acta Odontol Scand. 2003;61(6):356-362.

40. Walker-Engström ML, Ringqvist I, Vestling O, Wilhelmsson B, Tegelberg Å. A prospective randomized study comparing two different degrees of mandibular advancement with a dental appliance in treatment of severe obstructive sleep apnea. Sleep Breath. 2003;7(3): 119-130.

41. Alchanatis M, Zias N, Deligiorgis N, et al. Comparison of cognitive performance among different age groups in patients with obstructive sleep apnea. Sleep Breath. 2008;12(1):17-24.

42. Redline S, Strauss ME, Adams N, et al. Neuropsychological function in mild sleep-disordered breathing. Sleep. 1997;20(2):160-167.

43. Kim HC, Young T, Matthews CG, Weber SM, Woodward AR, Palta M. Sleep-disordered breathing and neuropsychological deficits. A population-based study. Am J Respir Crit Care Med. 1997;156(6): 1813-1819.

44. Boland LL, Shahar E, Iber C, et al. Measures of cognitive function in person with varying degrees of sleep-disordered breathing: the Sleep Heart Health Study. J Sleep Res. 2002;11(3):265-272.

45. Ayalon L, Ancoli-Israel S, Aka AA, McKenna BS, Drummond SP. Relationship between obstructive sleep apnea severity and brain activation during a sustained attention task. Sleep. 2009;32(3): 373-381.

46. Castronovo V, Canessa N, Strambi LF, et al. Brain activation changes before and after PAP treatment in obstructive sleep apnea. Sleep. 2009;32(9):1161-1172.

47. Ayalon L, Ancoli-Israel S, Klemfuss Z, Shalauta MD, Drummond SP. Increased brain activation during verbal learning in obstructive sleep apnea. Neuroimage. 2006;31(4):1817-1825.

\section{Dovepress}

original research, clinical \& epidemiological studies, reviews \& evaluations, case reports and extended reports. The manuscript management system is completely online and includes a very quick and fair peerreview system, which is all easy to use. Visit http://www.dovepress.com/ testimonials.php to read real quotes from published authors. 